\title{
A 20-year experience with isolated pericardiectomy: Analysis of indications and outcomes
}

Erin A. Gillaspie, MD, ${ }^{\mathrm{a}}$ John M. Stulak, MD, ${ }^{\mathrm{a}}$ Richard C. Daly, MD, ${ }^{\mathrm{a}}$ Kevin L. Greason, MD, ${ }^{\mathrm{a}}$ Lyle D. Joyce, MD, PhD, ${ }^{\mathrm{a}}$ Jae Oh, MD, ${ }^{\mathrm{b}}$ Hartzell V. Schaff, MD, ${ }^{\mathrm{a}}$ and Joseph A. Dearani, $\mathrm{MD}^{\mathrm{a}}$

\section{ABSTRACT}

Objectives: Outcome after pericardiectomy depends on many factors, but no large study has provided clarity on the effects of patient variables or cause of pericarditis on patient survival. We report early and late results from a 20-year experience with isolated pericardiectomy.

Methods: From January 1993 to December 2013, 938 patients underwent pericardiectomy at our institution. In order to establish a homogeneous population to analyze the impact of pericardiectomy, we excluded patients with prior chest radiation, malignancy, and concomitant valvular or coronary procedures. We identified a cohort of 521 who underwent isolated pericardiectomy; of these, 513 patients gave consent for research and comprise the cohort for this analysis; median age at operation was 57 years (range, $18-84$ years) and 363 (71\%) were men. Indications for pericardiectomy were effusive/chronic relapsing pericarditis in $158(31 \%)$ and pericardial constriction in $355(69 \%)$. Prior coronary artery bypass grafting had been performed in 84 patients $(14 \%)$. Median preoperative left ventricular ejection fraction was $60 \%$ (range, $24 \%-80 \%$ ), and $77 \%$ of patients were in New York Heart Association (NYHA) functional class III/IV.

Results: Surgical approach was median sternotomy in 412 (80\%), left thoracotomy in $71(14 \%)$, and clamshell in $30(5 \%)$. Extent of pericardial resection was radical in $414(81 \%)$, subtotal in $71(14 \%)$, and completion in $28(5 \%)$. Cardiopulmonary bypass was used in $205(40 \%)$. Overall mortality was $12 / 513(2.3 \%)$; $3 / 158(1.9 \%)$ for the effusive/chronic relapsing group versus $9 / 355(2.5 \%)$ for the constriction group $(P=.65)$. In the absence of multivariate predictors, which could not be identified, univariate predictors associated with increased risk of early death included lower left ventricular ejection fraction (hazard ratio [HR], $1.09 ; P=.03$ ) and preoperative renal insufficiency (HR, 9.9; $P<.001)$. Median duration of follow-up was 29 months (maximum 20.5 years) and overall 5-, 10 -, and 15 -year survival was $80 \%, 60 \%$, and $38 \%$, respectively. Overall survival according to surgical indication was higher in the effusive/chronic relapsing group when compared with the constriction cohort $(P<.001)$. Independent predictors associated with increased risk of overall mortality identified on multivariate analysis included older age (HR, 1.05; 95\% confidence interval [CI], [1.03, 1.07]; $P<.001$ ), congestive heart failure (HR, 1.49; 95\% CI, [1.03, 2.2]; $P=.02$ ), diabetes (HR, 1.83; 95\% CI, [1.2, 2.7]; $P=.004)$, completion pericardiectomy (HR, $2.4 ; 95 \% \mathrm{CI},[1.2,4.7] ; P=.01$ ), and chronic obstructive pulmonary disease (HR, $2.45 ; 95 \% \mathrm{CI},[1.5,3.9] ; P=.004)$. During the follow-up period, $80 \%$ of patients were free from NYHA functional class III/IV symptoms at 5 years and $78 \%$ at 10 years.

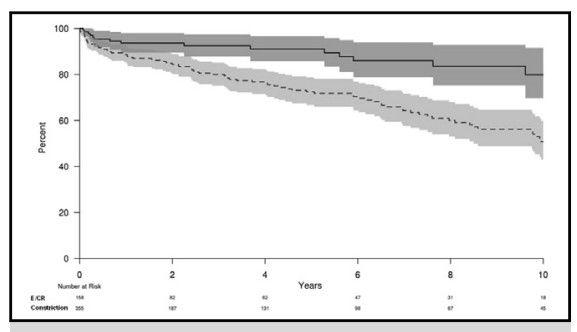

Late survival is different after pericardiectomy depending on indication for surgery.

\section{Central Message}

Early mortality after isolated pericardiectomy is low irrespective of the indication for surgery, and the majority of patients were free from significant heart failure symptoms during follow-up.

\section{Perspective}

There are many reports validating the benefit of pericardiectomy, but there remains a poor understanding of which patients derive the most benefit from surgery, what comorbid conditions contribute most to postoperative morbidity and mortality, the superiority of a particular surgical approach or, most importantly, the longterm outcomes after intervention.

See Editorial Commentary page 459.
From the Divisions of ${ }^{\mathrm{a}}$ Cardiovascular Surgery and ${ }^{\mathrm{b}}$ Cardiovascular Diseases, Mayo Clinic and Foundation, Rochester, Minn.

Read at the 95th Annual Meeting of The American Association for Thoracic Surgery, Seattle, Washington, April 25-29, 2015.

Received for publication May 9, 2015; revisions received March 17, 2016; accepted for publication March 20, 2016; available ahead of print May 20, 2016.
Address for reprints: John M. Stulak, MD, Division of Cardiovascular Surgery, Mayo Clinic College of Medicine, 200 First St SW, Rochester, MN 55905 (E-mail: stulak. john@mayo.edu). $0022-5223 / \$ 36.00$

Copyright (C) 2016 Published by Elsevier Inc. on behalf of The American Association for Thoracic Surgery

http://dx.doi.org/10.1016/j.jtcvs.2016.03.098 

Abbreviations and Acronyms
$\mathrm{CABG}=$ coronary artery bypass grafting
$\mathrm{CHF}=$ congestive heart failure
COPD $=$ chronic obstructive pulmonary disease
$\mathrm{HR}=$ hazard ratio
IABP $=$ intra-aortic balloon pump
$\mathrm{LV} E F=$ left ventricular ejection fraction
MI = myocardial infarction
NYHA $=$ New York Heart Association

\begin{abstract}
Scanning this QR code will take you to a video of the meeting presentation of this manuscript.
\end{abstract}

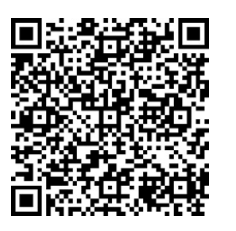

Conclusions: Whereas early mortality after isolated pericardiectomy is low irrespective of the indication for surgery, late follow-up demonstrates better outcomes after pericardiectomy for effusive/chronic relapsing pericarditis compared with pericardial constriction. Importantly, the majority of patients were free from significant heart failure symptoms during follow-up. (J Thorac Cardiovasc Surg 2016;152:448-58)

The history of pericarditis dates back hundreds of years with the first known written reference by Richard Lower in 1669. He described dyspnea and intermittent pulse in a patient with constrictive pericarditis. The first successful "decortication of the heart," as it was titled, in the United States was performed in 1928, in Boston, by Dr Churchill on an 18-year-old girl manifesting with marked cardiac decompensation. Over the years, more elegant descriptions of clinical presentation have emerged and pericarditis was subclassified into constrictive and effusive types. ${ }^{1,2}$

The true incidence of pericarditis in the general population is not known as it can be insidious and painless and thus go undiagnosed; however, general estimates indicate approximately $6 \%$ have signs of pericarditis at autopsy and this diagnosis accounts for approximately $1 / 1000$ of hospital admissions. ${ }^{3}$ The management of patients with pericarditis can be challenging. Whereas some patients may be managed successfully with medication, there is a subset of patients with pericardial constriction or medically refractory effusive/chronic relapsing pericarditis who benefit from surgical intervention. ${ }^{3,4}$ Despite having vastly different pathophysiology - constriction with loss of pericardial compliance and resultant diastolic heart failure and effusive/chronic relapsing pericarditis with recurrent chest pain and pericardial effusion-both benefit from removal of the pericardium to achieve symptomatic relief and improvement in functional status. ${ }^{3-9}$ Although, there are many reports validating the benefit of pericardiectomy, there remains a poor understanding of which patients derive the most benefit from surgery, ${ }^{4,10-13}$ what comorbid conditions contribute most to postoperative morbidity and mortality, the superiority of a particular surgical approach, or, most importantly, the long-term outcomes after intervention.

This study sought to evaluate outcomes in a large cohort of patients undergoing isolated pericardiectomy and to analyze indication, comorbid conditions, surgical approach, extent of resection, early morbidity, and mortality, as well as long-term freedom from relapse. Our goal was to elucidate the factors predicting worse outcome in order to enable counseling of patients preoperatively and anticipate clinical outcomes postoperatively.

\section{PATIENTS AND METHODS}

The Mayo Foundation Institutional Review Board approved this study, and all patients or their families gave written informed consent. Demographic and other patient-related data were obtained from Mayo Clinic medical records and our prospective clinical database. Follow-up information was obtained from subsequent clinic visits, written correspondence from local physicians, and mailed questionnaires to patients or families. Early operative mortality was defined as death occurring within 30 days of operation or any time during the index hospitalization. Late mortality was defined as death occurring after index hospitalization dismissal and during the follow-up period.

\section{Patients}

From January 1993 to December 2013, 938 patients underwent pericardiectomy at our institution. In order to establish a homogeneous population to analyze the impact of isolated pericardiectomy, patients with prior chest radiation, malignancy, and concomitant valvular or coronary procedures were excluded. We identified 521 patients who underwent isolated pericardiectomy; of these, 513 patients gave consent to be included in the study.

\section{Preoperative Data}

Median age at operation was 57 years (range, 18-84 years) and 363 patients $(71 \%)$ were men. Indication for pericardiectomy was constriction in 355 patients $(69 \%)$ and effusive/chronic relapsing in 158 patients $(31 \%)$. Causes of pericarditis in the constriction group included idiopathic in 205 $(58 \%)$, prior cardiac surgery in $110(31 \%)$, chronic pericarditis in $10(3 \%)$, infectious in $16(5 \%)$, and other in $14(4 \%)$. Patients with effusive/chronic relapsing pericarditis were further subclassified into specific indication for surgery: pain in 81 patients, constriction in 54, and effusion in 23 . The hemodynamic effects of effusive/chronic relapsing pericarditis were also noted. There were no hemodynamic perturbations in 91 patients, constrictive physiology was present in 54 , and tamponade in 7 . Prior pericardial window or other drainage procedure was performed in 24/158 (15\%) patients in the chronic relapsing/effusive group, with 2 having undergone prior incomplete pericardiectomy.

Prior cardiac surgery was performed in 105 patients (20\%), with 84 patients having undergone coronary artery bypass grafting (CABG) and 28 having undergone previous pericardiectomy. New York Heart Association 
TABLE 1. Preoperative clinical characteristics present in the study cohort

\begin{tabular}{lcc}
\hline \multicolumn{1}{c}{ Variable } & $\begin{array}{c}\text { Inflammatory/ } \\
\text { effusive }(\mathbf{N}=\mathbf{1 5 8}),\end{array}$ & $\begin{array}{c}\text { Constriction } \\
(\mathbf{N}=\mathbf{3 5 5}), \\
\mathbf{n}(\%)\end{array}$ \\
\hline Diabetes & $17(11)$ & $78(22)$ \\
Hypertension & $47(30)$ & $151(43)$ \\
COPD & $3(2)$ & $24(7)$ \\
PVD & $5(3)$ & $30(8)$ \\
Renal insufficiency & $5(3)$ & $19(6)$ \\
Prior surgery & $0(0)$ & $105(30)$ \\
Prior MI & $7(4)$ & $23(6)$ \\
Median LV EF, \% (range) & $60(24-80)$ & $60(30-80)$ \\
\hline
\end{tabular}

$C O P D$, Chronic obstructive pulmonary disease; $P V D$, peripheral vascular disease; $M I$, myocardial infarction, $L V E F$, left ventricular ejection fraction.

(NYHA) functional class at the time of operation was III/IV in $77 \%$ of patients. Median preoperative left ventricular ejection fraction (LV EF) was $60 \%$ (range, $24 \%-80 \%$ ). Other preoperative comorbid conditions are presented in Table 1.

\section{Statistical Analysis}

Continuous data were expressed as median value with a range (minimum-maximum), and included preoperative LV EF, age at operation, cardiopulmonary bypass time, and duration of follow-up. These 2 variables were not normally distributed and non-parametric analyses were performed. Data between 2 groups were compared using chi-square test for categorical variables. A backward stepwise Cox regression analysis was used to identify perioperative variables independently affecting outcomes. Variables to be included in the univariate analysis were selected a priori according to comorbidities thought to represent clinical importance from the literature and our clinical knowledge, including age $(\Delta 10 \%)$, LV EF $(-\Delta 10 \%)$, use of cardiopulmonary bypass, extent of resection, surgical approach, cause, diabetes, hypertension, chronic obstructive pulmonary disease (COPD), peripheral vascular disease, previous myocardial infarction (MI), renal insufficiency, congestive heart failure (CHF), extent of resection, and prior coronary bypass grafting. A parsimonious model was then identified using stepwise selection, with the criterion for inclusion in the final model being an $\alpha$ level of $<0.05$. Kaplan-Meier survival analysis was used to evaluate time-related outcomes and produce plots, which were subsequently compared using the log-rank test. Statistical significance was considered at $P<.05$.

\section{RESULTS}

\section{Operative Data}

All patients underwent isolated pericardiectomy. Some patients had concomitant, non-cardiac procedures including lung decortication in 11 patients, diaphragm plication in 1 , lung biopsy in 1, and mediastinal lymph node biopsy in 1 .

TABLE 2. Surgical approach employed in the study cohort

\begin{tabular}{lccc}
\hline & $\begin{array}{c}\text { Entire cohort } \\
(\mathbf{N}=\mathbf{5 1 3}),\end{array}$ & $\begin{array}{c}\text { Inflammatory/ } \\
\text { effusive }(\mathbf{N}=\mathbf{1 5 8}),\end{array}$ & $\begin{array}{c}\text { Constriction } \\
(\mathbf{N}=\mathbf{3 5 5}), \\
\text { Surgical approach }\end{array}$ \\
$\mathbf{n}(\%)$ & $\mathbf{n}(\%)$ & $\mathbf{n}(\%)$ \\
\hline Median sternotomy & $416(81)$ & $129(82)$ & $286(81)$ \\
Left thoracotomy & $71(14)$ & $24(15)$ & $47(13)$ \\
Clamshell & $30(5)$ & $6(3)$ & $24(6)$ \\
\hline
\end{tabular}

TABLE 3. Extent of pericardial resection performed in the study cohort

\begin{tabular}{lccc}
\hline $\begin{array}{l}\text { Extent of } \\
\text { resection }\end{array}$ & $\begin{array}{c}\text { Entire cohort } \\
(\mathbf{N}=\mathbf{5 1 3}), \\
\mathbf{n}(\%)\end{array}$ & $\begin{array}{c}\text { Inflammatory/ } \\
\text { effusive }(\mathbf{N}=\mathbf{1 5 8}), \\
\mathbf{n}(\%)\end{array}$ & $\begin{array}{c}\text { Constriction } \\
(\mathbf{N}=\mathbf{3 5 5}), \\
\mathbf{n}(\%)\end{array}$ \\
\hline Radical & $417(81)$ & $142(90)$ & $275(77)$ \\
Subtotal & $72(14)$ & $14(8)$ & $58(16)$ \\
Completion & $28(5)$ & $3(2)$ & $25(7)$ \\
\hline
\end{tabular}

Cardiopulmonary bypass was used in 207/513 patients (40\%): 181/355 (51\%) of the constriction group and 26/ 158 patients $(16 \%)$ in the effusive/chronic relapsing $(P<.001)$. The overall median cardiopulmonary bypass time was 60 minutes (range, 7-213 minutes), which was similar between the constriction group (60 minutes, range, 7-213 minutes) and the effusive/chronic relapsing group (50 minutes, range, 12-180 minutes); $(P=.22)$. The surgical approach is presented in Table 2. Pericardiectomy was approached in most patients by median sternotomy and was not different between the constriction and effusive/ chronic/relapsing groups $(81 \%$ vs $82 \%, P=.45)$. The extent of pericardial resection performed is presented in Table 3. A radical resection, defined as removal of anterior, inferior, and left lateral pericardium posterior to the left phrenic nerve, was performed most commonly in both groups, but was more common in the effusive/chronic relapsing group than in the constriction group $(90 \%$ vs $77 \%, P<.001)$.

\section{Early Outcomes}

Early morbidity is presented in Table 4 and most commonly included atrial arrhythmias in 66 patients $(13 \%)$, prolonged ventilation in $55(11 \%)$, and renal failure in $26(5 \%)$. Early mortality occurred in $12 / 513(2.3 \%)$; $9 /$ $355(2.5 \%)$ because of constriction pericarditis and $3 / 158$ $(1.9 \%)$ because of effusive/chronic relapsing pericarditis $(P=.65)$. Causes of early death included sepsis/multisystem organ failure in 5 patients, cardiogenic shock in 4 ,

TABLE 4. Early nonfatal morbidity observed in the study cohort

\begin{tabular}{lc}
\hline \multicolumn{1}{c}{ Variable } & $\begin{array}{c}\text { Number of } \\
\text { patients } \mathbf{( \% )}\end{array}$ \\
\hline Atrial arrhythmias & $66(13)$ \\
Prolonged ventilation & $55(11)$ \\
Renal failure & $26(5)$ \\
Pneumonia & $17(3)$ \\
Dialysis & $13(3)$ \\
Gastrointestinal complications & $15(3)$ \\
Low cardiac output/IABP & $13(3)$ \\
Mediastinal hemorrhage/re-exploration & $15(3)$ \\
Wound infection & $6(1)$ \\
Stroke & $4(1)$ \\
\hline IABP, Intra-aortic balloon pump.
\end{tabular}

IABP, Intra-aortic balloon pump. 


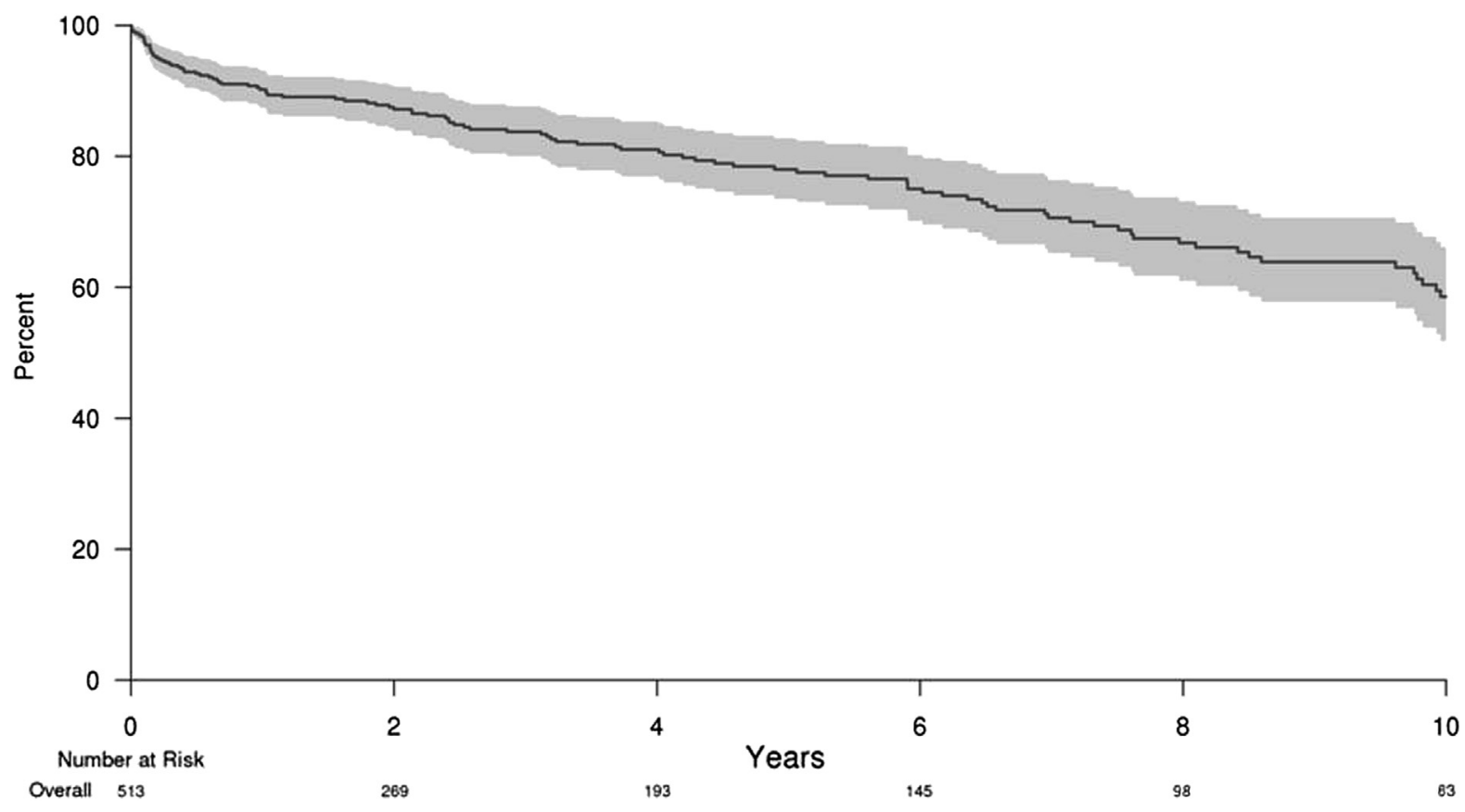

FIGURE 1. Late survival for all patients undergoing isolated pericardiectomy.

ventricular arrhythmias in 2 , and hypercarbic respiratory failure in 1. Univariate predictors associated with increased risk of early death included lower LV EF (10\% decrement in LV EF) (HR, 1.09; 95\% confidence interval [CI], [1.01, 1.2]; $P=.03$ ) and preoperative renal insufficiency (defined as creatinine $>2.0)(\mathrm{HR}, 9.9 ; 95 \% \mathrm{CI},[2.8,35.3] ; P<.001)$.
There were insufficient early events to identify multivariate predictors of early death.

\section{Late Outcomes}

Median duration of late follow-up was 29 months (maximum 20.5 years). Overall 5-, 10-, and 15-year

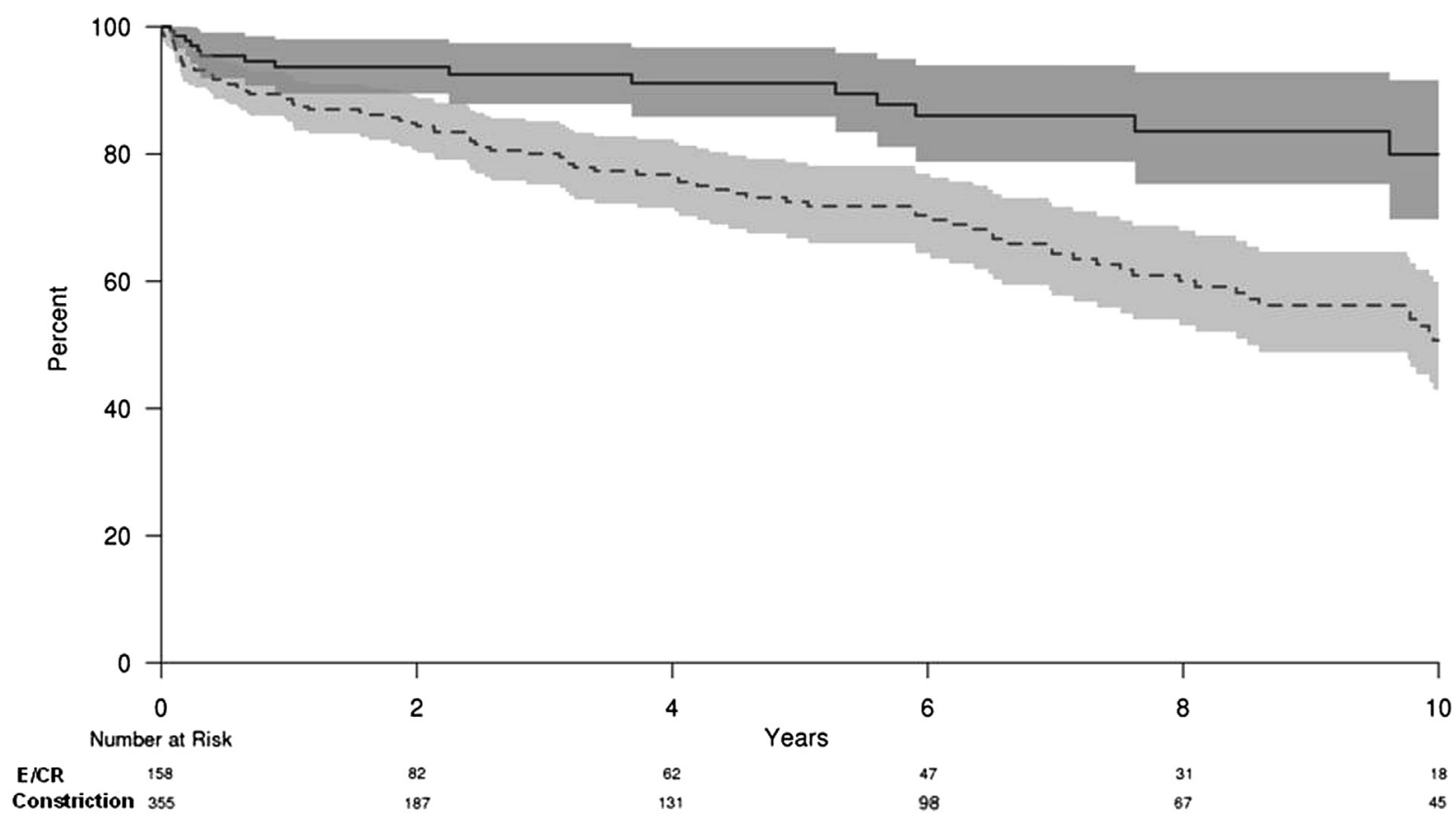

FIGURE 2. Late survival according to preoperative indication for pericardiectomy. Late survival is significantly higher when performed for effusive/ chronic relapsing pericarditis (solid line) compared with pericardial constriction (dotted line) $(P<.001)$. E/CR, Effusive/chronic relapsing group. 


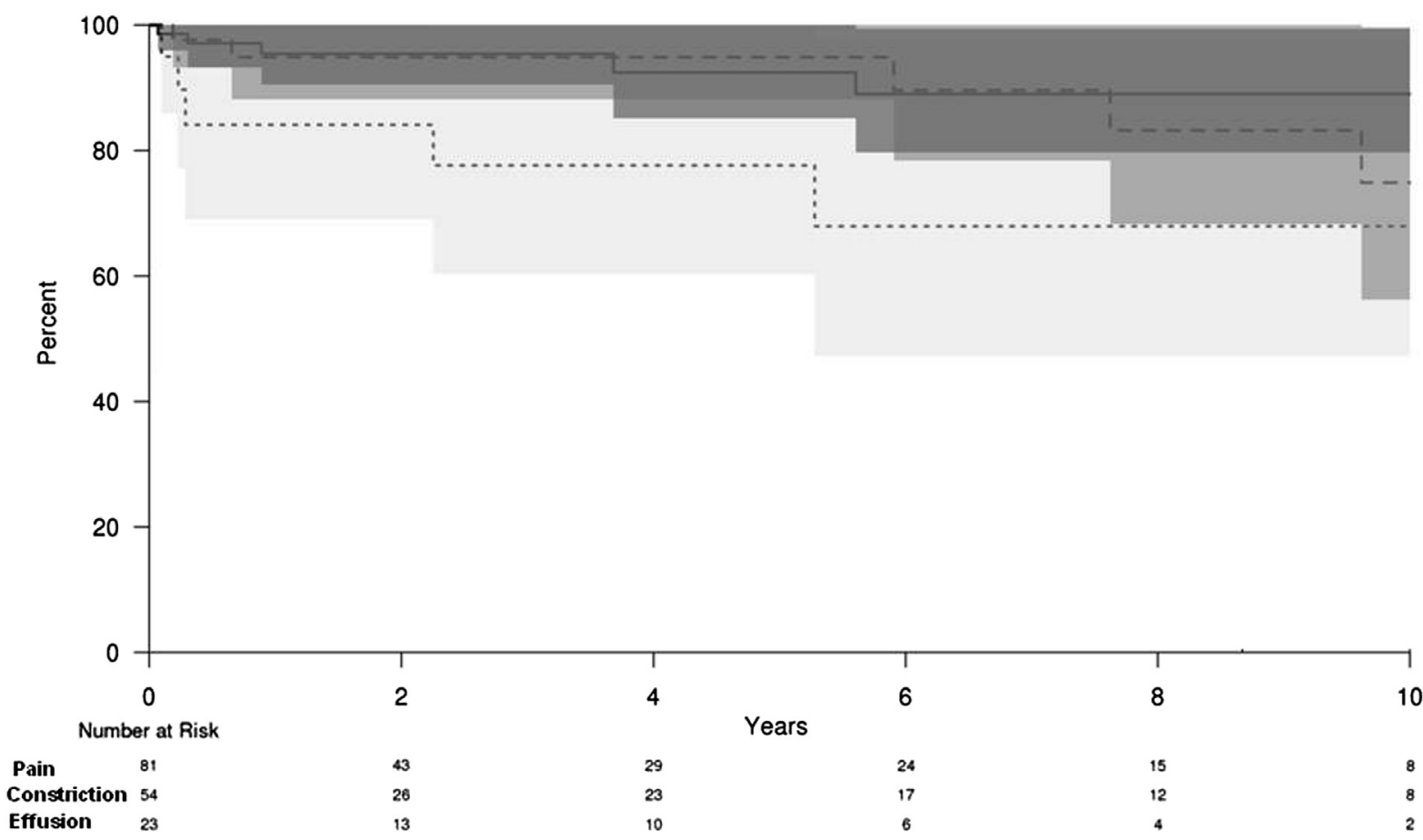

FIGURE 3. Late survival for patients undergoing pericardiectomy for effusive/chronic relapsing pericarditis according to specific preoperative indication, including pain (solid line), constriction (dashed line), and effusion (dotted line). A significantly lower survival was observed in patients with a pericardial effusion $(P=.034)$.

survival was found to be $80 \%, 60 \%$, and $38 \%$, respectively (Figure 1); $33 \%, 13 \%$, and $3 \%$ of patients were at risk at 5-, $10-$, and 15 year follow-up intervals, respectively. Overall survival according to surgical indication was higher in the effusive/chronic relapsing group than in the constriction group $(P<.001)$ (Figure 2$)$. Late survival was also analyzed

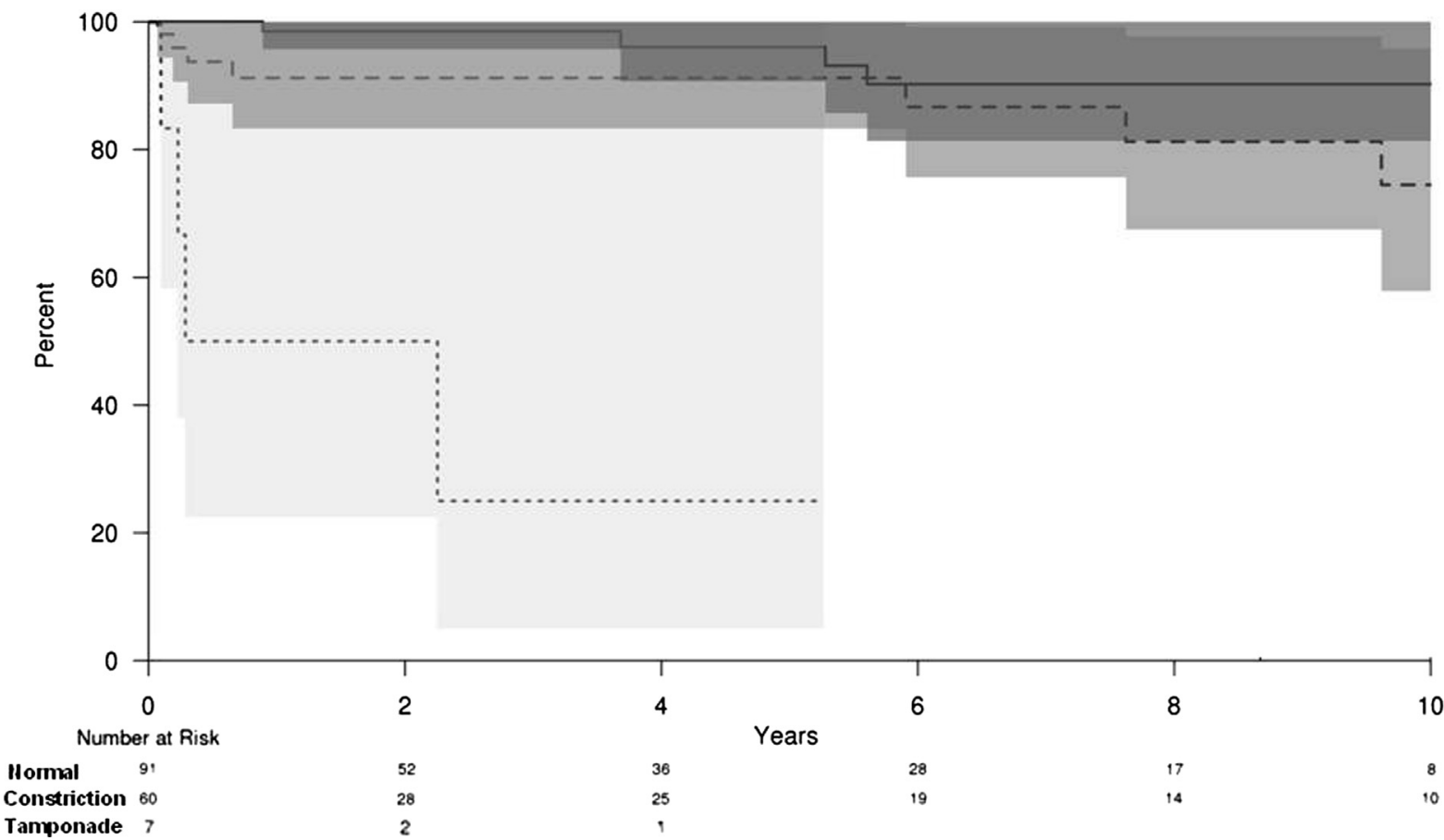

FIGURE 4. Late survival for patients undergoing pericardiectomy for effusive/chronic relapsing pericarditis according to type of physiology present at operation, including normal (solid line) versus constriction (dashed line) versus tamponade (dotted line). A significantly lower survival was observed in patients with tamponade physiology $(P<.001)$. 
TABLE 5. Univariate predictors associated with late survival in the entire cohort

\begin{tabular}{lllc}
\hline \multicolumn{1}{c}{ Variable } & $\begin{array}{c}\text { Hazard } \\
\text { ratio }\end{array}$ & $\begin{array}{c}\mathbf{9 5} \% \\
\text { confidence } \\
\text { limits }\end{array}$ & P value \\
\hline Age & 1.05 & $1.03,1.07$ & $<.001$ \\
Cardiopulmonary bypass & 1.51 & $1.04,2.2$ & .03 \\
Effusive/chronic relapsing & 0.38 & $0.22,0.63$ & $<.001$ \\
Diabetes & 2.86 & $1.93,4.23$ & $<.001$ \\
COPD & 2.2 & $1.41,3.43$ & $<.001$ \\
CHF & 1.85 & $1.28,2.67$ & .001 \\
Prior CABG & 2.2 & $1.5,3.33$ & $<.001$ \\
Completion pericardiectomy & 2 & $1.02,3.85$ & .035 \\
Renal insufficiency & 2.2 & $1.1,4.13$ & .022 \\
LV EF & 1 & $0.98,1.03$ & .74 \\
Sternotomy approach & 1.5 & $0.79,2.9$ & .21 \\
Hypertension & 1.4 & $0.94,1.96$ & .1 \\
PVD & 1.65 & $0.98,2.77$ & .06 \\
Previous MI & 0.99 & $0.55,1.76$ & .96 \\
Subtotal pericardiectomy & 0.7 & $0.34,1.48$ & .36 \\
\hline
\end{tabular}

COPD, Chronic obstructive pulmonary disease; $C H F$, congestive heart failure; $C A B G$, coronary artery bypass grafting; $L V E F$, left ventricular ejection fraction; $P V D$, peripheral vascular disease; $M I$, myocardial infarction.

by indication for pericardiectomy in the effusive/chronic relapsing group. Interestingly, within the effusive/chronic relapsing group, time-related survival was significantly lower among the differing indications for surgery $(P=.034)$ (Figure 3). Finally, survival was assessed based on preoperative hemodynamic compromise in the effusive/chronic relapsing group $(P<.001)$ (Figure 4$)$. Univariate predictors associated with increased risk of lower overall survival are presented in Table 5. Independent predictors associated with increased risk of lower overall survival for the entire cohort on multivariate analysis included older age (HR, 1.05 for each increasing decade; 95\% CI, [1.03, 1.07]; $P<.001$ ), CHF (HR, 1.49; 95\% CI, [1.03, 2.2]; $P=.02$ ), diabetes (HR, 1.83 ; $95 \% \mathrm{CI}$, [1.2, 2.7]; $P=.004)$, completion pericardiectomy (HR, 2.4; 95\% CI, [1.2, 4.7]; $P=.01$ ), and COPD (HR, 2.45; 95\% CI, [1.5, 3.9]; $P=.004)$. During follow-up, $80 \%$ of patients were free from NYHA functional class III/IV symptoms at 5 years and $78 \%$ were free at 10 years. When analyzed separately, patients in the effusive/chronic relapsing group had too few late events for multivariable predictors associated with increased risk of lower overall survival to be obtained. In the constriction group, older age (HR, 1.04; 95\% CI, [1.02, 1.06]; $P<.0$ 01), CHF (HR, 1.7; 95\% CI, [1.1, 2.5]; $P=.014)$, COPD (HR, 2; 95\% CI, [1.2, 3.5]; $P=.012$ ), and diabetes (HR, $2.2 ; 95 \% \mathrm{CI},[1.4,3.4] ; P=.004)$ were all predictors associated with increased risk of lower overall survival. Type of approach (median sternotomy, left thoracotomy, or clamshell) was not associated with differences in overall survival $(P=.23)$.
Four patients required redo pericardiectomy during the follow-up period, 3 in the constriction group and 1 in the effusive/chronic relapsing group.

\section{COMMENT}

Historically, pericardiectomy has been reported to have a very high early morbidity and mortality for both constriction $(14 \%)^{14}$ and effusive/chronic relapsing types $(5.5 \%$ $19.4 \%) .{ }^{15}$ However, postoperative mortality in our series was low $(2.3 \%)$ and is similar to contemporary reports demonstrating that pericardiectomy can be performed with low early risk in the current era. ${ }^{3,4}$ It has been postulated that earlier diagnosis and surgical intervention before the onset of irreversible left ventricular dysfunction and end-organ damage has likely contributed to the more recent improved outcomes. In fact, our study confirmed that lower preoperative LV EF and renal insufficiency both contributed to increased early mortality, albeit in a univariate manner. This perhaps underscores the importance of earlier recognition of disease and referral in these patients.

Overall survival is $80 \%$ at 5 years and $60 \%$ at 10 years, with outcomes favoring patients with effusive/chronic relapsing pericarditis. There were insufficient late events to perform multivariate analysis to determine independent predictors of either early or overall mortality in the effusive/chronic relapsing subgroup. It should be noted that patients undergoing operation for an effusion, and in particular those with tamponade physiology, did have lower late survival. In the constrictive pericarditis group, older age, chronic obstructive lung disease, diabetes, and poorer NYHA functional class score predicted a worse survival.

The observed cause of pericarditis depends highly on several factors, including region of the world ${ }^{9-11,13}$ and surgical era. ${ }^{14,16}$ Further, with the current prevalence of cardiac surgical procedures and increased use of electrophysiological interventions, iatrogenic pericarditis is at an all-time high. ${ }^{17,18}$ Furthermore, at our institution in $1982,73 \%$ of cases were deemed idiopathic compared with only $18 \%$ in the study period 1996-2006; during this time, causes attributable to surgery rose to $34 \%$. These observations are in distinct contrast to other regions, such as Asia, Africa, and India, in which tuberculosis is recognized as a major cause ranging from $61 \%$ to $93 \%{ }^{4,9-13}$ The numerous causative factors predisposing to the development of pericarditis poses a challenge in evaluating its natural history and outcomes after surgical treatment. Because of this, we deliberately selected a homogeneous cohort of patients; choosing patients who were undergoing isolated pericardiectomy in an effort to better define the natural postoperative history, but avoiding the potentially confounding influence of other procedures. Radiation-induced constriction was also not included in this study. No other studies to date have accrued a similarly large and specific group of patients for 
study. Importantly, whereas we did report our findings for the cohort as a whole, we also performed subgroup analysis on our 2 main indications for pericardiectomy; because the constriction and effusive/chronic relapsing groups represent 2 distinct disease processes. The subgroup analysis is not meant to be comparative, as this would not be clinically useful, but rather give more relevance to the data as we tailor treatments to individual patients with a unique combination of comorbid conditions and pathology.

Patients with constrictive pericarditis present with heart failure, which can manifest with a broad range of symptoms depending on the severity of cardiac compromise. Constriction may be progressive, ultimately resulting in end-organ damage and deterioration of cardiac function. Medical therapy is limited in constriction patients, with the focus on improving symptoms of heart failure and temporizing measures. Surgery is the only definitive treatment. Effusive/ chronic relapsing patients present most commonly with recurring episodes of pain and less commonly with compressive effusions and constriction. Non-steroidal anti-inflammatory drugs and corticosteroids are the mainstay of medical therapy in effusive/chronic relapsing pericarditis. Patients with large effusions additionally benefit from pericardial drainage. In many cases pericardial reaction will improve with the aforementioned treatments and patients may successfully be observed. There is a subset of patients who will have recurring episodes of inflammation manifesting with refractory pain and some who progress to demonstrate evidence of constriction because of long-standing inflammation. ${ }^{4,5}$ Patients undergoing surgery for effusive/chronic relapsing pericarditis tended to have fewer relapses and hospitalizations than patients managed medically. Interestingly, in our subgroup analysis comparing chronic relapsing patients with constriction patients did not show worse late outcome; however, patients with effusion had lower long-term survival. The patients with effusion presenting with tamponade had a significantly worse survival, and we believe this accounted in large part for the observed overall lower survival for this subgroup of patients. However, it is very important to acknowledge the small numbers in this subgroup of patients presenting with tamponade, and that firm conclusions are difficult to draw from this.

Findings at operation are also unique in these 2 subgroups of patients. Typically, patients with constrictive pericarditis manifest with a heavily calcified, thickened pericardium which is intimately associated with, at times, extensions of calcium into the myocardium. In these cases, the pericardial space is obliterated and separation is tedious. Conversely, effusive/chronic relapsing pericarditis exhibits an inflamed, non-calcified pericardium that is generally not adherent to the underlying edematous epicardium. In some cases, a thickened pericardium is not present; this does not portend a lesser response to pericardiectomy. ${ }^{19}$
The extent of pericardiectomy is a much-debated topic and therefore lacks standardization. An anterior pericardiectomy removes only the anterior pericardium between both phrenic nerves. A complete pericardiectomy removes not only the anterior pericardium as described above, but also the inferior (diaphragmatic) and left lateral pericardia (posterior to the left phrenic nerve) ${ }^{20}$ Of course care is taken to preserve each phrenic nerve, with monitoring as indicated.

Pericardiectomy, in the face of severe constriction and heavy calcification can be technically demanding surgery, wrought with potential complications. For this reason, some investigators advocate anterior pericardiectomy only in this scenario, with acceptable results, ${ }^{21}$ whereas others have found that survival and functional outcome are superior with complete pericardiectomy. ${ }^{4}$ There has been no demonstrable, statistically significant difference in surgical risk between complete pericardiectomy versus a lesser resection. ${ }^{4}$ Often in difficult pericardiectomies, an outer rind can be easily removed, but a second tight covering over the epicardial surface perpetuates constriction. When complete removal is not possible, the epicardial peel may be quadriculated to produce non-contiguous islands of constricting epicardium. The hemodynamic consequence of the remaining pericardium is not felt to compromise the end result. Notably, our study, along with a published report by our colleagues Drs Dearani and Schaff in 2012 demonstrate re-operation with completion pericardiectomy to be independently associated with lower survival on multivariate analysis. ${ }^{22}$ Our data did not show the extent of resection to be significant when evaluating the long-term outcomes of surgery (radical vs subtotal).

Because this report spans 2 decades and includes numerous surgeons, it is not surprising that surgical approach, use of cardiopulmonary bypass, and extent of resection varies. Median sternotomy was employed most commonly; however, some surgeons preferred left thoracotomy or clamshell approach. Certainly, it must be noted that a left thoracotomy limits exposure of the right phrenic nerve and could compromise completeness of resection. Cardiopulmonary bypass was used less frequently in the effusive/chronic relapsing group for the aforementioned less-adherent pericardium which allows for easier removal. The use of cardiopulmonary bypass was associated with a lower late survival in this study, but only in a univariate manner. We believe this is a reflection of a sicker patient population with a more calcified and adherent pericardium.

\section{Limitations}

This study intentionally selected only patients undergoing isolated pericardiectomy to better understand the natural postoperative history. Patients undergoing concomitant revascularization or valvular procedures were eliminated. Moreover, this study did not include patients who had constrictive pericarditis as a consequence of radiation 
therapy, which we believe represents a different disease process. These results will not be generalizable to all patients undergoing pericardiectomy. Also, this is a retrospective review spanning several decades. Surgical approach was selected by each individual surgeon and was not standardized. However, approach to surgery did not manifest with any differences in outcome. Finally, late follow-up was not available in all patients, as is anticipated in any review of this nature. Admittedly, this could affect the prevalence of late mortality in our series. However, we have no reason to believe that patients who were lost to follow-up had worse outcome. In, fact it is possible that patients who were more available for follow-up were self-selected owing to a higher complexity or presence of other clinical features including postoperative valvular disease or ongoing left ventricular dysfunction.

\section{CONCLUSIONS}

Isolated pericardiectomy for constriction or for effusive/ chronic relapsing pericarditis can be performed safely with low morbidity and mortality. Although the surgical approach and use of cardiopulmonary bypass differed between providers, neither of these factors proved significant in assessing outcomes. Although late outcome was superior in patients with the effusive/chronic relapsing subtype of pericarditis, symptomatic benefit was seen in the majority of patients at follow-up with a statistically significant reduction in NYHA functional class.

\section{Webcast}

You can watch a Webcast of this AATS meeting presentation by going to: http://www.jtcvsonline.org/article/S00225223(16)30280-X/addons.

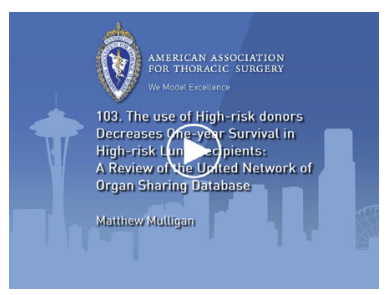

\section{Conflict of Interest Statement}

Authors have nothing to disclose with regard to commercial support.

\section{References}

1. Fowler N. Constrictive pericarditis: its history and current status. Clin Cardiol. 1995; 18:341-50.

2. Churchill E. Decortication of the heart (Delorme) for adhesive pericarditis. Arch Surg. 1929; 19:1457-69.

3. Syed FF, Schaff HV, Oh JK. Constrictive pericarditis - a curable diastolic heart failure. Nat Rev Cardiol. 2014;11:530-44.

4. Khandaker MH, Schaff HV, Greason KL, et al. Pericardiectomy vs. medical management in patients with relapsing pericarditis. Mayo Clin Proc. 2012;87: 1062-70.

5. Ling LH, Oh JK, Schaff HV, et al. Constrictive pericarditis in the modern era: evolving clinical spectrum and impact on outcome after pericardiectomy. Circulation. 1999;100:1380-6.

6. Chowdry UK, Subramaniam GK, Kumar AS, et al. Pericardiectomy for constrictive pericarditis: a clinical echocardiographic, and hemodynamic evaluation of two surgical techniques. Ann Thorac Surg. 2005;81:522-9.

7. Ghavidel AA, Gholampour M, Kyavar M, Mirmesdagh Y, Tabatabaie MB Constrictive pericarditis treated by surgery. Tex Heart Inst J. 2012;39:199-205.

8. Yetkin U, Kestelli M, Yilik L, et al. Recent surgical experience in chronic constrictive pericarditis. Tex Heart Inst J. 2003;30:27-30.

9. Szabo G, Schmack B, Bulut C, et al. Constrictive pericarditis: risks, aetiologies and outcomes after total pericardiectomy: 24 years of experience. Eur J Cardiothorac Surg. 2013;44:1023-8.

10. Mutyaba AK, Balkaran S, Cloete R, et al. Constrictive pericarditis requiring pericardiectomy at Groote Schuur Hospital, Capetown, South Africa: causes and perioperative outcomes in the HIV era (1990-2012). J Thorac Cardiovasc Surg. 2014;148:3058-65.

11. Avgerinos D, Rabitnokov Y, Worku B, Neragi-Miandoab S, Girardi LN. Fifteenyear experience and outcomes of pericardiectomy for constrictive pericarditis J Card Surg. 2014;4:434-8.

12. Buyukbayrak F, Aksoy E, Tas S, Kirali K. Surgical management of effusive constrictive pericarditis. Cardiovasc J Afr. 2013;8:303-7.

13. Tokuda Y, Miyata H, Motomura N, et al. Outcome of pericardiectomy for constrictive pericarditis in Japan: a Nationwide outcome study. Ann Thorac Surg. 2013;2:571-6.

14. McCaughan BC, Schaff HV, Piehler JM, et al. Early and late results of pericardiectomy for constrictive pericarditis. J Thorac Cardiovasc Surg. 1985;85:340-50.

15. Piehler JM, Pluth JR, Schaff HV, Danielson GK, Orszulak TA, Puga FJ. Surgical management of effusive pericardial disease. Influence of extent of pericardial resection on clinical course. J Thorac Cardiovasc Surg. 1985;90:506-16.

16. Ling LH, et al. Detection of constrictive pericarditis: a single-center experience of 523 surgically confirmed cases [abstract]. J Am Coll Cardiol. 2009;53:A176.

17. Bartus K, et al. Percutaneous left atrial appendage suture ligation using the LARIAT device in patients with atrial fibrillation: initial clinical experience J Am Coll Cardiol. 2013;62:108-18.

18. Jahaveri A, Glassberg HL, Acker MA, Callans DJ, Goldberg LR. Constrictive pericarditis presenting as a late complication of epicardial ventricular tachycardia ablation. Circ Heart Fail. 2012;5:e22-3.

19. Taljera DR, Edwards WD, Danielson GK, et al. Constrictive pericarditis in 26 patients with histologically normal pericardial thickness. Circulation. 2003;108:1852-7.

20. Villavicencio MA, Dearani JA, Sundt TM. Pericardiectomy for constrictive or recurrent inflammatory pericarditis. Oper Techniq Thorac Cardiovasc Surg. 2008; 13:2-13.

21. Nataf P, Cacoub P, Dorent R, et al. Results of subtotal pericardiectomy for constrictive pericarditis. Eur J Cardiothorac Surg. 1993;7:252-6.

22. Cho YH, Schaff HV, Dearani JA, et al. Completion pericardiectomy for recurrent constrictive pericarditis: importance of timing of recurrence on late clinical outcome of operation. Ann Thorac Surg. 2012;93:1236-41.

Key Words: pericardium, constriction, diastolic heart failure

\section{Discussion}

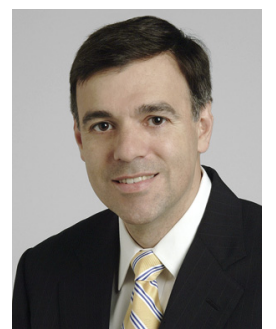

Dr J. Sabik (Cleveland, Ohio). Drs Sundt, Pomar, members, and guests. I would like to congratulate Dr Gillaspie and colleagues on a fine presentation and thank them for providing me with a copy of their manuscript prior to this meeting.

They report on a 20 -year experience with surgical pericardiectomy from the Mayo Clinic. During this period, 938 patients underwent pericardiectomy for either constriction or effusive chronic relapsing 
pericarditis. After removing patients with prior radiation, over 500 patients were available for analysis. Multiple incisions, such as median sternotomy, clamshell, and left thoracotomy were employed, as well as different extension of pericardial resection, such as radical, subtotal, and completion. The hospital results are excellent, with a low hospital mortality of only $2.3 \%$. They should be congratulated, and it is for this reason why they cannot find any multivariable predictors of early mortality. Their long-term survival was $80 \%$ at 5 years and $60 \%$ at 10 years.

I have 2 questions for Dr Gillaspie. My first question has to do with your follow-up. Although this is a 20year series, I was surprised to see that your median duration of late follow-up was only 29 months. In your manuscript, you state follow-up was obtained by clinic visits, correspondence from local physicians, or mailed questionnaires. Was follow-up only opportunistic or was there a closing date or anniversary follow-up where you actively attempted to follow-up with all of your patients, or is the short median follow-up due to the fact that the majority of the cases were performed toward the end of your series?

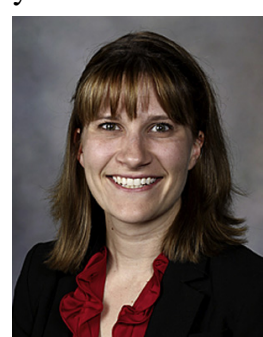

Dr Gillaspie. Thank you very much for your question. We did not have a specific anniversary at which we followed up with our patients. However, pericardiectomies have always been a topic of interest for the Mayo Clinic and it's something that both Dr Schaff and Dr Dearani have published on extensively in the past. For that reason, we have performed intermittent mailings over the years to touch base with all of our patients in our database. We aimed to find out how they're doing and in some cases to follow up with their physicians as well.

So we were able to collect additional data through those mailings, which included one follow-up in the early 2000s, around 2005, and a second one around 2010. In addition, many of the patients, as you did mention, underwent surgery toward the end of our series and so we have much shorter follow-up in them. As you probably noticed, our 20-year follow-up really only included about 16 patients.

Dr Sabik. I would encourage you to think about maybe following up these patients, because I think that although you answered some beautiful questions, what we would really like to know as surgeons is what we do as surgeons that makes a difference. You have a wonderful 20-year experience with 500 patients that underwent different surgical procedures. Possibly if you would have followed up the patients maybe a little bit more closely you might be able to identify more events, which would then help us decide which procedures we should do. So I encourage you to go back and follow those.

Dr Gillaspie. Thank you.

Dr Sabik. My second question has to do with how surgeons at the Mayo Clinic perform pericardiectomies today. As expected in this 20-year series, the approach and extent of pericardial resection varied. How have your findings changed the practice at the Mayo Clinic and what incision and how extensive a pericardiectomy do the Mayo Clinic surgeons perform today?

Dr Gillaspie. Thank you so much for that question. I'm really glad to have the opportunity to discuss this a little bit further.

Still, just like in the study, the majority of our surgeries are approached by a median sternotomy. Based on both the study and one published by Dr Dearani and Dr Schaff a few years ago, the most commonly performed extent is a complete pericardiectomy, which includes an anterior, inferior, and left lateral pericardiectomy. This has been shown in several studies not to have an increased mortality rate versus just an anterior pericardiectomy.

The other important finding is that redo surgery, in particular completion pericardiectomy, confers a worse outcome not only in our studies but in many others. So performing the absolute best extent of resection you can at the outset is very important.

Understandably, in the constrictive pericarditis group in particular, there can be extensive calcifications and sometimes it is not possible to perform a very complete pericardiectomy; you can risk damage to very important underlying structures. In those cases we generally quadriculate the calcifications so that we don't leave a large island of calcium overlying the ventricles. Instead, we leave smaller islands and allow the ventricle to bulge in between.

Dr Sabik. Thank you.

Dr J. Pomar (Barcelona, Spain). I have 1 question. You mentioned the cases where you have a big calcification, you cannot resect it, and this is something that is clear, but what about patients who have localized anterior and maybe diaphragmatic calcification? You can resect them, but the posterior is free of calcium and looks like normal pericardium. Do you think the evolution is going to be a bad prognosis and better to remove everything, or what do you think is better to do?

Dr Gillaspie. I think that's an outstanding question. It's always hard to know how the pericardium is going to progress. In the patients who are coming back for redo pericardiectomies, the pericardium probably looked normal lateral to the phrenic nerve and inferiorly as well at the time of the initial surgery. However, because of the worse outcomes in patients who have to come back for surgery, I think it's best to perform the most complete pericardiectomy that you can. 
Dr Pomar. But I agree with you that a longer follow-up would be very important to make a decision on what kind of technique we use.

Dr T. MacGillivray (Boston, Mass). I congratulate you on a great and very informative presentation. I was intrigued by your constrictive pericarditis group and its outcomes. In our experience, it can be very challenging to differentiate between constrictive pericarditis and a restrictive cardiomyopathy. One would think that if you had constrictive pericarditis that resecting the pericardium should cure that disease, and of course if it was a restrictive myocardial process, it would really have no effect.

So as you look back on these patients, were there any patients that were initially diagnosed with constrictive disease that actually had restrictive disease?

Dr Gillaspie. Yes, there were some patients. Unfortunately, the diagnosis, as you mentioned, can be challenging. One of the big reasons that we actually excluded the radiation group was because we felt that these patients were presenting with exactly what you described, a restrictive process. These patients have a disease of their pericardium, a disease of their myocardium, a disease of their coronaries, and of their valve, and we felt that this really confounded studying pericardial disease. So by eliminating the group that had radiation, we felt that we diminished some of the patients who were presenting with a restrictive process. But, yes, there was a subset of patients in our analysis who did not have an improvement in New York Heart Association score and probably were presenting with a restrictive process as opposed to a constrictive process.

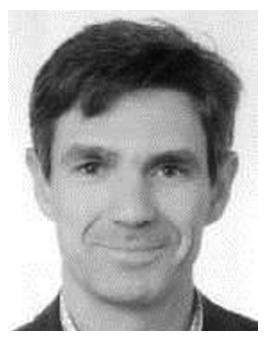

Dr P. Ballaux (Gent, Belgium). A very nice presentation. Excellent results. I wonder, is there a reason not to do a pericardiectomy on the right side?

Dr Gillaspie. In reviewing the literature, there actually is not a whole lot of consensus on even what defines a complete pericardiectomy. At our institution we define it by anterior, left lateral, and inferior. But you're absolutely right, at other institutions and in some of the studies that I have read, there are some people who actually do an additional dissection posterior to the phrenic nerve on the right and take out that portion as well. If you can do it safely, I don't think there is any reason not to. It is just not how we have standardly built our practice.

Dr Ballaux. You want only to resect the pericardium around the ventricles? Do you think there is less impact on the right atrium?

Dr Gillaspie. I think that generally the phrenic nerve is quite lateral, there is minimal pericardium posteriorly and you don't have quite as much calcification in that area. Therefore not much impact on the right atrium and cardiac function.

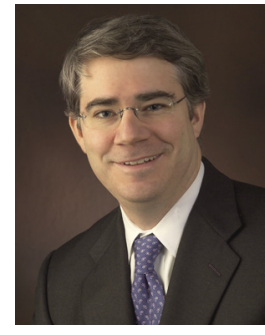

Dr T. Gleason (Pittsburgh, Pa). A very nice presentation. Could you expand on the effusive group a bit more, particularly the workup. In some of them the indication was pain. Did they also get right heart caths and was there a hemodynamic indication associated with that? How did you decide who to operate on when pain was the primary indication?

Dr Gillaspie. Absolutely, and it was a little bit variable in that group. In some patients it was failure of medical treatment. They had been on chronic corticosteroids and/or immunosuppressants for some time, chronic repeat hospitalizations, and that was really the driving force in taking them to the operating room to try and perform a definitive treatment for them to avoid the recurrences.

In 54 of our patients with effusive pericarditis, they developed a constrictive physiology. The constrictive effusive group is quite different from the chronic calcific pericarditis group in that they initially present with effusions. In these patients, even after the effusions drainage of the pericardial effusion they have ongoing constriction. This is likely secondary to the chronic inflammation that they have sustained, and this is a secondary constrictive type physiology.

Our preoperative work up generally included a chest Xray, an echocardiogram, CT scans so we could evaluate the extent of calcification, as well as a hemodynamic cath. The hemodynamic cath is not performed in all cases; it is reserved for cases in which a diagnosis cannot be made on echocardiogram. Our cardiologists in many circumstances feel very confident making a diagnosis on echocardiogram based on 3 major findings. But in some patients the diagnosis can be quite challenging and we do go on to perform a hemodynamic cath to confirm the diagnosis.

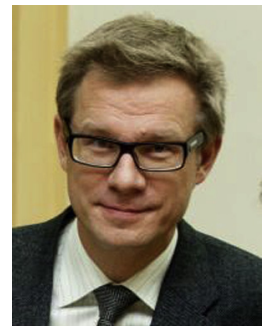

Dr M. Deja (Katowice, Poland). I enjoyed your presentation very much Two questions. The first being, did you look at the right-sided failure symptoms as a predictor of an outcome versus the left-sided failure? And the second question being, with your immense experience, what is at the moment the level of the disease you operate, what is the trigger, the symptoms or hemodynamics? What are your indications for operation?

Dr Gillaspie. To answer your second question first, the indications for operation could be quite variable between the 2 groups. Generally speaking, in the constrictive pericarditis group we were seeing progressive right heart failure and progressive diastolic dysfunction. Some of our patients were referred to us quite late. In fact, many had been worked up for hepatic dysfunction, undergone multiple 
paracenteses, and had long-standing symptoms of pretty significant heart failure before having a diagnosis made for constrictive pericarditis.

So some patients were very far along in their disease process before they were ever even referred to our clinics.

As for the effusive group, some had undergone multiple drainage attempts, pericardial windows, repeat catheterbased drainages of their pericardium with ongoing recurrence of effusions. Some patients presented with tamponade type physiology, some of them requiring repeat hospitalizations, long courses of corticosteroids, at which point they were referred to us for evaluation.

Dr Deja. Are there patients that you operate on with very little symptoms, just based on hemodynamics?

Dr Gillaspie. There are some patients, particularly in the effusive group, who were operated on for pain and ongoing medication requirements, in particular corticosteroids and immunosuppressants, and fewer hemodynamic manifestations. They were more than likely in a New York Heart Association class I to II as opposed to the III or IV which we saw more commonly in the chronic calcific pericarditis group.

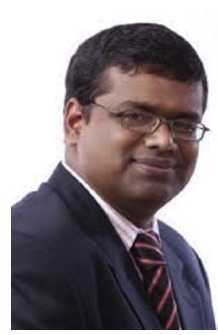

Dr S. Bhate (Puna, India). Why did you require pericardiectomy on cardiopulmonary bypass?

Dr Gillaspie. It depended by surgeon. Some of them, as you probably noticed, had quite short bypass times. There were circumstances in which a patient did not tolerate the hemodynamically consequences of lifting the heart and therefore a short bypass run was used to facilitate inferior or more lateral dissection. Sometimes it was a very short run really just to achieve a complete dissection.

In other cases, the pericardium was so densely adherent it was just felt to be safer to be able to decompress the heart, manipulate the heart, or to perform quadriculation under cardiopulmonary bypass.

Finally, some surgeons just prefer that method.

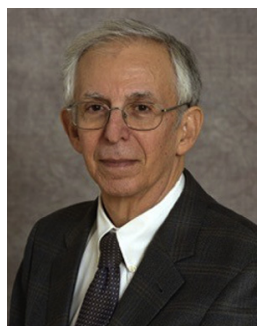

Dr H. Spotnitz (New York, NY). It used to be said that the sequence of resection was essential to keep patients out of pulmonary edema and also that removal of the pericardium could actually push patients over the top of their Starling curve because their ventricles had already undergone involution. Have those considerations all gone away?

Dr Gillaspie. I don't think those considerations have gone away. In fact, some of our consultants prefer to admit patients ahead of time to perform aggressive diuresis with intra-aortic balloon pumps in place, with Swan-Ganz catheters in place to try and get a patient to a very comfortable place on the Starling curve before even attempting a pericardiectomy. It depends greatly on how the patients presented initially.

You are absolutely right, that's always a consideration when taking patients to the operating room. 